\title{
General Psychiatry Unexpected cancellation on a catatonic patient's electroconvulsive therapy due to the coronavirus pandemic
}

Kelsey Casano (D) , ${ }^{1}$ Erin Capone ${ }^{2}$

To cite: Casano K, Capone E. Unexpected cancellation on a catatonic patient's electroconvulsive therapy due to the coronavirus pandemic. General Psychiatry 2020;33:e100271. doi:10.1136/ gpsych-2020-100271

Received 22 June 2020 Revised 23 July 2020 Accepted 01 August 2020

Check for updates

(C) Author(s) (or their employer(s)) 2020. Re-use permitted under CC BY-NC. No commercial re-use. See rights and permissions. Published by BMJ.

'Department of Psychiatry, LSU Health Sciences Center New Orleans, New Orleans, Louisiana, USA

${ }^{2}$ Psychiatry, LSU Health Sciences Center New Orleans, New Orleans, Louisiana, USA

Correspondence to

Dr Erin Capone;

ecapon@|suhsc.edu

\section{ABSTRACT}

We report a case of a 39-year-old woman with a psychiatric history of schizoaffective disorder with catatonia, dependent personality disorder and substance use disorder whose symptoms have been very difficult to control. During her most recent inpatient admission, she was treated with electroconvulsive therapy (ECT) for catatonia. Our treatment team was hopeful that ECT was making a difference for this patient. However, she was only able to receive two sessions of treatment due to new hospital protocols related to the coronavirus pandemic. Although the patient was not suspected to have the coronavirus, she could no longer undergo ventilation with a bag and mask during the procedure. Bag-mask ventilation is known to aerosolise the coronavirus and other diseases and potentially put healthcare workers at risk. Although orotracheal intubation also aerosolises the coronavirus, this was the only means of airway management still allowed by anaesthesia providers at this time. Our psychiatry team estimated that the risks of intubation outweighed the benefits of treatment, and ECT was cancelled.

Without additional ECT treatments, the patient again decompensated for several weeks before being stabilised on clozapine, haloperidol and lorazepam. Although she eventually had a positive treatment outcome, her hospital course was likely prolonged due to unforeseen events related to the novel coronavirus. We feel that the current medical climate is unprecedented and is interfering with necessary psychiatric treatment in an unanticipated way. Anaesthesiologists will need to be flexible while working with psychiatrists and identify safe ways to provide this necessary psychiatric treatment for patients.

\section{INTRODUCTION}

Electroconvulsive therapy (ECT) was first described in the 1930s after several schizophrenic patients showed symptomatic improvement following spontaneous seizure activity. ${ }^{1}$ In modern practice, ECT is performed by placing electrodes on a patient's scalp and delivering an electric pulse to induce seizure activity. It is an extremely effective therapy for treatmentresistant major depression, catatonia, mania and schizophrenia. ECT has proven particularly efficacious in the treatment of catatonia, regardless of the aetiology. ${ }^{2}$ Because of this,
ECT is considered the preferred treatment for patients with catatonia who fail to respond to adequate dosages of benzodiazepines. ${ }^{2}$

During ECT, a patient is placed under general anaesthesia and given muscle relaxants. The patient is oxygenated with a bag and face mask during the procedure. In rare instances, patients may require endotracheal intubation to secure the airway instead. ${ }^{3} 4$ This is generally avoided because it requires the patient to spend more time under anaesthesia. ${ }^{4}$ Also, intubation is not without risk and has the potential to cause severe airway trauma such as life-threatening tears of the trachea and larynx. Reports of such injuries, which sometimes result in death and significant litigation, are not uncommon. ${ }^{5}$ Additionally, there is one known report of a patient who was intubated during ECT and suffered a tracheal tear during the procedure. This resulted in life-threatening pneumomediastinum and pneumopericardium for the patient. ${ }^{6}$

We report a case of a 39-year-old woman with psychiatric history of schizoaffective disorder with catatonia, dependent personality disorder and substance use disorder whose symptoms have been very difficult to control with antipsychotics and benzodiazepines. During her most recent inpatient admission, she was treated with ECT for refractory catatonia. She underwent two sessions of ECT with the bag and mask and began to respond quite well to this therapy. However, due to new hospital protocols related to the coronavirus pandemic, bag-mask ventilation was no longer an option, and our treatment team was forced to choose whether to intubate the patient and proceed with therapy or to call off treatment altogether.

\section{CASE HISTORY}

We report a case of a 39-year-old Caucasian woman with a psychiatric history of schizoaffective disorder with catatonia, dependent 
personality disorder and substance use disorder. Her psychiatric history began at age 23 years with her first psychotic episode. Since then, she has been hospitalised multiple times with treatment-resistant symptoms coupled with low treatment adherence outside of the hospital. She was a victim of sex trafficking and domestic abuse and has attempted suicide by overdose. She has a history of alcohol, marijuana, cocaine and heroin use. She was able to graduate from high school and attended college for 1 year but has remained unemployed since then. She was last hospitalised 3 weeks prior to this current admission, at which time she was stabilised on oral aripiprazole before being discharged to live with her mother.

During this current inpatient admission, the patient was brought to the hospital by her mother due to altered mental status and mutism. On presentation to the emergency room, there was a concern for catatonia and possible serotonin syndrome secondary to an oral aripiprazole overdose. Urine toxicology and alcohol levels were negative. She was subsequently admitted to inpatient medicine service for observation and supportive care, which included lorazepam. She was seen by psychiatry, and serotonin syndrome was deemed unlikely. She endorsed visual hallucinations, so lorazepam was discontinued, and she was started on low-dose haloperidol. On medical clearance, she was transferred to inpatient psychiatry. Haloperidol was increased and lorazepam was restarted due to concern for catatonia. She continued to exhibit severe psychomotor retardation and was unable to verbally respond to questions. These symptoms exhibited mild improvement with increasing doses of haloperidol and lorazepam over the next few weeks; however, due to a lack of significant progress, the decision was made to proceed with ECT in this patient.

During the first ECT session, the patient experienced a seizure of $150 \mathrm{~s}$, which was prolonged and required propofol to abort without incident. Afterwards, she showed improvement with a significant decrease in latency of response time in her speech. She underwent her second session 3 days later and experienced a seizure of $82 \mathrm{~s}$. Once again, she seemed in brighter spirits after treatment with resolving catatonia and decreased response latency compared with previous days.

Our treatment team was hopeful that ECT was helping this patient. However, before beginning the third session of ECT, coronavirus hit the USA. With the virus came a new series of hospital protocols, and although the patient was not suspected to have coronavirus, she could no longer undergo ventilation with a bag and mask during ECT. Bag-mask ventilation is known to aerosolise the coronavirus and potentially put healthcare workers at risk. Although orotracheal intubation is also known to aerosolise the coronavirus, this was the only means of airway management still allowed by anaesthesia providers. Our psychiatry team felt that the risks of intubation outweighed the benefits of treatment, and ECT was cancelled indefinitely.
Without additional ECT treatments, the patient decompensated. She displayed emotional lability, disorganised thoughts and behaviours, and eventually lapsed back into a state of catatonia with increased latency of response and severe psychomotor retardation. We started the patient on clozapine, a medication that she had previously responded to but had been non-compliant with in the past. We tapered the haloperidol. Lorazepam was continued at $1 \mathrm{mg}$ three times per day due to repeated recurrence of catatonia on taper attempts. Clozapine was eventually increased to $200 \mathrm{mg}$ per day, and haloperidol was tapered to $10 \mathrm{mg}$ per day. The patient responded well to this treatment and had minimal side effects. With time, she gained more insight on her situation and showed resolving symptoms of catatonia. She became linear, cooperative, pleasant and able to speak about aspects of her life with a good memory. After 8 weeks in the hospital, she finally met criteria for discharge. She was discharged to live with her husband and father-in-law with the agreement to follow-up with the assertive community team on a frequent basis.

\section{DISCUSSION AND CONCLUSIONS}

Although this patient was eventually stabilised on medication and suitable for discharge, her hospital course was likely prolonged due to novel barriers to treatment during the coronavirus pandemic. We feel that the current medical climate is unprecedented and is interfering with necessary psychiatric treatment in unanticipated ways. Mentally ill persons comprise an extremely vulnerable patient population with many barriers to receiving appropriate care, and it is apparent that the coronavirus is introducing new barriers for these patients to receive treatment. Anaesthesiologists will need to be flexible while working with psychiatrists and identify safe ways to provide this necessary psychiatric treatment for patients. Bag-mask ventilation and intubation both aerosolise the coronavirus and potentially put healthcare workers' lives at risk, but bag-mask airway management poses far fewer risks for the patient. New protocols such as preoperative coronavirus testing and more robust personal protective equipment are needed to ensure the safety of healthcare workers while delivering necessary medical treatment to patients.

Contributors Both authors made substantial contributions to the conception of the work, and drafted and revised the work.

Funding The authors have not declared a specific grant for this research from any funding agency in the public, commercial or not-for-profit sectors.

Competing interests None declared.

Patient consent for publication Not required.

Provenance and peer review Not commissioned; externally peer reviewed.

Open access This is an open access article distributed in accordance with the Creative Commons Attribution Non Commercial (CC BY-NC 4.0) license, which permits others to distribute, remix, adapt, build upon this work non-commercially, and license their derivative works on different terms, provided the original work is properly cited, appropriate credit is given, any changes made indicated, and the use is non-commercial. See: http://creativecommons.org/licenses/by-nc/4.0/. 
ORCID iD

Kelsey Casano http://orcid.org/0000-0002-1834-9185

\section{REFERENCES}

1 Endler NS. The origins of electroconvulsive therapy (ECT). Convuls Ther 1988;4:5-23.

2 Weiner RD, Reti IM. Key updates in the clinical application of electroconvulsive therapy. Int Rev Psychiatry 2017;29:54-62.
3 Kellner $\mathrm{CH}$, Bryson EO. Anesthesia advances add to safety of ECT. Psychiatric Times 2012;29.

4 Chawla N. Anesthesia for electroconvulsive therapy. Anesthesiol Clin 2020;38:183-95.

5 Cook TM, Scott S, Mihai R. Litigation related to airway and respiratory complications of anaesthesia: an analysis of claims against the NHS in England 1995-2007. Anaesthesia 2010;65:556-63.

6 Hutchens M, Smith KR. A case of tracheal injury with intubation during electroconvulsive therapy. J Ect 2009;25:67-9.

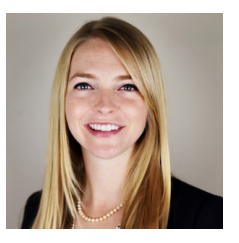

Kelsey Casano obtained a bachelor's degree of Arts from Tulane University in 2015. After this, she attended Louisiana State University School of Medicine in New Orleans where she developed a passion for communitybased healthcare and psychiatry. She graduated as a Doctor of Medicine in May 2020. She is currently spending the 2020-2021 academic year studying to acquire her Master of Public Health. She plans to pursue a career in psychiatry beginning next year. Her main research interest include health disparities among mentally ill populations and their families, and policy changes that could improve quality of life for these groups. 